NBER WORKING PAPER SERIES

\title{
RECURSIVE COMPETITIVE EQUILIBRIUM
}

\author{
Rajnish Mehra \\ Working Paper 12433 \\ http://www.nber.org/papers/w12433
}

\section{NATIONAL BUREAU OF ECONOMIC RESEARCH 1050 Massachusetts Avenue Cambridge, MA 02138}

August 2006

Prepared for the The New Palgrave Dictionary of Economics, 2nd edition. The views expressed herein are those of the author(s) and do not necessarily reflect the views of the National Bureau of Economic Research.

C2006 by Rajnish Mehra. All rights reserved. Short sections of text, not to exceed two paragraphs, may be quoted without explicit permission provided that full credit, including (C) notice, is given to the source. 
Recursive Competitive Equilibrium

Rajnish Mehra

NBER Working Paper No. 12433

August 2006

JEL No. D5, D51, D53, D61, D91, D92, E21, E22, E23, G12

\title{
ABSTRACT
}

In this article we define a Recursive Competitive Equilibrium, provide an example and review the related literature.

The article is an entry prepared for The New Palgrave: A Dictionary of Economics, 2nd Edition (Palgrave Macmillan: New York).

\author{
Rajnish Mehra \\ Department of Economics \\ University of California \\ Santa Barbara, CA 93106 \\ and NBER \\ mehra@econ.ucsb.edu
}




\section{Introduction}

The underlying structure of most dynamic business-cycle and consumption-based asset-pricing models is a variant of the neoclassical stochastic growth model. Such models have been analyzed by, among others, Cass (1965), Brock and Mirman (1972), and Donaldson and Mehra (1983). They focus on how an omniscient central planner seeking to maximize the present value of expected utility of a representative agent, optimally allocates resources over the infinite time horizon.

Production is limited by an aggregate production function subject to technological (total factor productivity) shocks. The solution to the planning problem is characterized by time-invariant decision rules, which determine optimal consumption and investment each period. These decision rules have as arguments the economy's period aggregate capital stock and the shock to technology.

Business cycles, however, are not predicated on the actions of a central planner, but arise from interactions among economic agents in competitive markets. Given the desirable features of the stochastic growth paradigm--the solution methods are well known and the model generates well-defined proxies for all the major macro aggregates: consumption, investment, output, etc.--it is natural to ask if the allocations arising in that model can be viewed as competitive equilibria. That is, do price sequences exist such that economic agents, optimizing at these prices and interacting through competitive markets, achieve the allocations in question as competitive equilibria? This is the essential question of dynamic-decentralization theory. 


\section{Alternative approaches to Dynamic Decentralization:}

\section{Valuation Equilibrium:}

One way of modeling uncertain dynamic economic phenomena is to use ArrowDebreu general equilibrium structures and to search for optimal actions conditional on the sequence of realizations of all past and present random variables or shocks. The commodities traded are contingent claim contracts. These contracts deliver goods (e.g., consumption and capital goods) at a future date, contingent on a particular sequential realization of uncertainty. Markets are assumed to be complete, so that for any possible future realization of uncertainty (sequence of technology shocks) up to and including some future period, a market exists for contracts that will deliver each good at that date contingent on that realization (event). This requires a very rich set of markets. All trading occurs in the first period: consumers contract to receive consumption and investment goods and to deliver capital goods in all future periods contingent on future states so as to maximize the expected present value of their utility of consumption over their infinite lifetimes. Firms choose their production plans so as to maximize the present value of discounted profits. Given current prices, they contract to deliver consumption and investment goods to, and to receive capital goods from the consumer-investors. Under standard preference structures, these contingent choices never need to be revised. That is, if markets reopen, no new trades will occur.

In its most general formulation, a Valuation Equilibrium is characterized simply as a continuous linear functional that assigns a value to each bundle of contingent 
commodities. Only under more restrictive assumptions can this function be represented as a price sequence (Bewley (1972), Prescott and Lucas (1972), Mehra (1988)). The basic

result is that for any solution to the planner's problem--that is, sequences of consumption, investment and capital goods--a set of state-contingent prices exists such that these sequences coincide with the contracted quantities in the Valuation Equilibrium.

This decentralization concept is quite broad and applies to central-planning formulations much more general than the neoclassical growth paradigm. It reminds us that the financial structure underlying the stochastic growth paradigm is fundamentally one of complete contingent commodity markets. Nevertheless, it is a somewhat unnatural perspective for macroeconomists (all macro policies must be announced at time zero), and it presumes a set of markets much richer than any observed. These shortcomings led to the development of the concept of a recursive competitive equilibrium.

\section{Recursive Competitive Theory:}

An alternative approach that has proved very useful in developing testable theories is to replace the attempt to locate equilibrium sequences of contingent functions with the search for time-invariant equilibrium decision rules. These decision rules specify current actions as a function of a limited number of "state variables" which fully summarize the effects of past decisions and current information. Knowledge of these state variables provides the economic agents with a full description of the economy's current state. Their actions, together with the realization of the exogenous uncertainty determines the values of the state variables in the next sequential time period. This is what is meant by a 
recursive structure. In order to apply standard time series methods to any testable implications, these equilibrium decision rules must be time invariant.

Recursive Competitive Theory was first developed by Mehra and Prescott (1977) and further refined in Prescott and Mehra (1980). These papers also establish the existence of a recursive competitive equilibrium and the supportability of the Pareto Optimal through the recursive price functions. Excellent textbook treatments are contained in Harris (1987), Stokey, Lucas and Prescott (1989) and Ljungqvist and Sargent (2004). Since its introduction, it has been widely used in exploring a vide variety of economic issues including business-cycle fluctuations, monetary and fiscal policy, trade related phenomena, and regularities in asset price co-movements ${ }^{1}$.

The recursive equilibrium abstraction postulates a continuum of identical economic agents indexed on the unit interval (again with preferences identical to those of the representative agent in the planning formulation), and a finite number of firms. As in the Valuation Equilibrium approach, consumers undertake all consumption and saving decisions. Firms, which have equal access to a single constant-returns-to-scale technology, maximize their profits each period and are assumed to produce two goods, a consumption good and a capital good. Unlike the Valuation Equilibrium approach, trading between agents and firms occurs every period ${ }^{2}$. At the start of each period, firms observe the technological shock to productivity and purchase capital and labor services, which are supplied inelastically at competitive prices. The capital and labor are used to produce the

\footnotetext{
${ }^{1}$ See for example Kydland and Prescott (1982), Long and Plosser (1983) and Mehra and Prescott (1985).
} 
capital and consumption goods. At the close of the period, individuals, acting competitively, use their wages and the proceeds from the sale of capital to buy the consumption and capital goods produced by the firms. Consumers then retain the capital good into the next period when it again becomes available to firms and the process repeats itself. Note that firms are liquidated at the end of each period (retaining no capital assets while technology is freely available), and that no trades between firms and consumerinvestors extend over more than one time period. Capital goods carried over from one period to the next are the only link between periods, and period prices depend only on the state variables in that period.

Formally, a Recursive Competitive Equilibrium (RCE) is characterized by time invariant functions of a limited number of 'state variables', which summarize the effects of past decisions and current information. These functions (decision rules) include (a) a pricing function, (b) a value function, (c) a period allocation policy specifying the individual's decision, (d) period allocation policy specifying the decision of each firm and (e) a function specifying the law of motion of the capital stock.

While the restrictive structure of markets and trades makes this concept less general than the Valuation Equilibrium Approach, it provides an interpretation of decentralization that is better suited to macro-analysis. More recently, the recursive equilibrium concept has been generalized to admit an infinitely-lived firm which maximizes its value. When a RCE is Pareto-optimal its allocation coincides with that of the

\footnotetext{
${ }^{2}$ This is in contrast to markets in an Arrow-Debreu setting where as mentioned earlier no trade would occur if markets were to reopen.
} 
associated planning problem. The solution to the central-planning stochastic-growth problem may then be regarded as the aggregate investment and consumption functions that would arise from a decentralized, recursive homogeneous consumer economy. We illustrate this with the help of an example below, which considers an economy with a single capital good. The reader is referred to Prescott and Mehra (1980) for the more general case with multiple capital types.

\section{An Example:}

Consider the simplest central planning stochastic growth paradigm

$$
w\left(k_{0}, \lambda_{0}\right)=\max E\left\{\sum_{t=0}^{\infty} \beta^{t} u\left(c_{t}\right)\right\}
$$

subject to

$c_{t}+k_{t+1} \leq \lambda_{t} f\left(k_{t}, l_{t}\right), \lambda_{0}, k_{0}$ given, $l_{t}=1 \forall t$

In this formulation, $u(\cdot)$ is the period utility function of a representative consumer defined over his period t consumption $c_{t} ; k_{t}$ denotes capital available for production in period $\mathrm{t}$ and $l_{t}$ denotes period $\mathrm{t}$ labor supply which is in-elastically supplied by the consumer-investor at $l_{t}=1$, for all t. The expression $f\left(k_{t}, l_{t}\right)$ represents the period technology (production function) which is shocked by the bounded stationary stochastic factor $^{3} \lambda_{t} . E$ denotes the expectations operator and the central planner is assumed to have rational expectations; that is, he uses all available information to rationally anticipate future variables. In particular he knows the conditional distribution of future technology

\footnotetext{
${ }^{3}$ It is assumed that $\lambda_{t}$ is subject to a stationary Markov process with a bounded ergodic set.
} 
shocks $F\left(\lambda_{t+1} ; \lambda_{t}\right)$. For the purposes of this example we restrict preferences to be

logarithmic and assume a Cobb-Douglas technology ${ }^{4}: u\left(c_{t}\right)=\ln c_{t}$ and $f\left(k_{t}, l_{t}\right)=k_{t}^{a} l_{t}^{1-a}$. We

also assume that $\alpha, \beta<1$ and that capital fully depreciates each period.

These conditions are sufficient to guarantee a closed form solution to the planning problem:

$$
\begin{aligned}
& c_{t}=(1-\alpha \beta) k_{t}^{\alpha} \lambda_{t}, \text { and } \\
& k_{t+1}=i_{t}=\alpha \beta k_{t}^{\alpha} \lambda_{t}
\end{aligned}
$$

where we identify as investment, $i_{t}$, the capital stock held over for production in period $\mathrm{t}+1$. These allocations are Pareto optimal.

We will show that the investment and consumption policy functions arising as a solution to this problem may be regarded as the aggregate investment and consumption functions arising from a decentralized homogenous consumer economy.

We first qualitatively describe the RCE underlying this model and then demonstrate the relevant equilibrium price and quantity functions explicitly. The one capital good is assumed to produce two goods - a consumer good and an investment (capital) good. At the beginning of each period, firms observe the shock to productivity $\left(\lambda_{t}\right)$ and purchase capital and labor from individuals at competitively determined rates. Both capital and labor are used to produce the two output goods. Individuals use their proceeds from the sale of capital and labor services to buy the consumption good $\left(c_{t}\right)$ and

\footnotetext{
${ }^{4}$ To the best of my knowledge, the parameterization in this example is the only one known to result in closed form solutions.
} 
the investment good $\left(i_{t}\right)$ at the end of the period. This investment good is used as capital $\left(k_{t+1}\right)$ available for sale to the firm next period and the process continues recursively.

To cast this problem formally as a recursive competitive equilibrium we introduce some additional notation. Let $k_{t}$ denote the capital holdings of a particular (measure zero) individual at time t, and $\underline{k}_{t}$ the distribution of capital amongst other individuals in the economy. This latter distinction allows us to make formal the competitive assumption: all the economic participants will assume that $\underline{k}_{t}$ is exogenous to them and that the price functions depend solely on this aggregate (in addition to the technology shock). Clearly, in equilibrium, $k_{t}=\underline{k}_{t}$ for our homogeneous consumer economy. In addition, let $p_{i}, p_{c}$ and $p_{k}$ be the price of the investment, consumption and capital goods respectively and $p_{l}$ be the wage rate. These prices are presumed to be functions of the economy wide state variables exclusively and all participants take these prices as given for their own decision making purposes. The 'state variables' characterizing the economy are $(\underline{k}, \lambda)$ and the individual are $(k, \underline{k}, \lambda)$.

We use the symbols $(c, i, k, l)$ to denote points in the "commodity space" for the firm and the consumer. The $c$ in the commodity point of the firm is a function specifying the consumption good supplied by the firm and is written $\operatorname{as} c^{s}\left(\underline{k}_{t}, \lambda_{t}\right)$. Similarly, the $c$ in the commodity point of the individual is the amount of the consumption good demanded 
by the individual and is written as $c^{d}\left(k_{t}, \underline{k}_{t}, \lambda_{t}\right)$. In equilibrium ${ }^{5}$, since the market clears, of course $c^{S}=c^{d}$. The same comments apply to the other elements of the commodity point.

In the decentralized version of this economy, the problem facing a typical household is

$$
v\left(k_{0}, \underline{k}_{0}, \lambda_{0}\right)=\max E\left\{\sum_{t=0}^{\infty} \beta^{t} \ln c^{d}\left(k_{t}, \underline{k}_{t}, \lambda_{t}\right)\right\}
$$

subject to

$$
\begin{aligned}
& p_{c}\left(\underline{k}_{t}, \lambda_{t}\right) c^{d}\left(k_{t}, \underline{k}_{t}, \lambda_{t}\right)+p_{i}\left(\underline{k}_{t}, \lambda_{t}\right) i^{d}\left(k_{t}, \underline{k}_{t}, \lambda_{t}\right) \leq p_{k}\left(\underline{k}_{t}, \lambda_{t}\right) k^{s}\left(k_{t}, \underline{k}_{t}, \lambda_{t}\right)+p_{l}\left(\underline{k}_{t}, \lambda_{t}\right) l^{s}\left(k_{t}, \underline{k}_{t}, \lambda_{t}\right) \\
& k_{t+1} \equiv k^{s}\left(k_{t+1}, \underline{k}_{t+1}, \lambda_{t+1}\right)=i^{d}\left(k_{t}, \underline{k}_{t}, \lambda_{t}\right), \\
& l^{s}\left(k_{t}, \underline{k}_{t}, \lambda_{t}\right) \leq 1 \\
& \text { and } \\
& \underline{k}_{t+1}=\psi\left(\underline{k}_{t}, \lambda_{t}\right) \text { is the law of motion of the aggregate capital stock }
\end{aligned}
$$

With capital and labor priced competitively each period, the firm's objective function is especially simple - maximize period profits. The firm's problem then is

$$
\begin{aligned}
& \max \left\{p_{c}\left(\underline{k}_{t}, \lambda_{t}\right) c^{s}\left(\underline{k}_{t}, \lambda_{t}\right)+p_{i}\left(\underline{k}_{t}, \lambda_{t}\right) i^{s}\left(\underline{k}_{t}, \lambda_{t}\right)-p_{k}\left(\underline{k}_{t}, \lambda_{t}\right) k^{d}\left(\underline{k}_{t}, \lambda_{t}\right)-p_{l}\left(\underline{k}_{t}, \lambda_{t}\right) l^{d}\left(\underline{k}_{t}, \lambda_{t}\right)\right\} \\
& \text { subject to } c_{t}^{s}+i_{t}^{s} \leq \lambda_{t}\left(k_{t}^{d}\right)^{\alpha}\left(l_{t}^{d}\right)^{1-\alpha}
\end{aligned}
$$

Via Bellman's Principle of Optimality, the recursive representation of the individual's problem $\mathrm{P} 2$ is

\footnotetext{
5 As mentioned earlier, in equilibrium $k_{t}=\underline{k}_{t}$
} 
$v\left(k_{t}, \underline{k}_{t}, \lambda_{t}\right)=\max _{\left\{c^{d}, i^{d}, l^{s}, k^{d}\right\}}\left\{\ln \left(c^{d}\left(k_{t}, \underline{k}_{t}, \lambda_{t}\right)\right)+\beta \int v\left(i^{d}\left(k_{t}, \underline{k}_{t}, \lambda_{t}\right), \psi\left(\underline{k}_{t}, \lambda_{t}\right), \lambda_{t+1}\right) d F\left(\lambda_{t+1} \mid \lambda_{t}\right)\right.$

\section{Subject to}

$p_{c}\left(\underline{k}_{t}, \lambda_{t}\right) c^{d}\left(k_{t}, \underline{k}_{t}, \lambda_{t}\right)+p_{i}\left(\underline{k}_{t}, \lambda_{t}\right) i^{d}\left(k_{t}, \underline{k}_{t}, \lambda_{t}\right) \leq p_{k}\left(\underline{k}_{t}, \lambda_{t}\right) k^{s}\left(k_{t}, \underline{k}_{t}, \lambda_{t}\right)+p_{l}\left(\underline{k}_{t}, \lambda_{t}\right) l^{s}\left(k_{t}, \underline{k}_{t}, \lambda_{t}\right)$

$k_{t+1} \equiv k^{s}\left(k_{t+1}, \underline{k}_{t+1}, \lambda_{t+1}\right)=i^{d}\left(k_{t}, \underline{k}_{t}, \lambda_{t}\right)$,

$l^{s}\left(k_{t}, \underline{k}_{t}, \lambda_{t}\right) \leq 1$

and

$\underline{k}_{t+1}=\psi\left(\underline{k}_{t}, \lambda_{t}\right)$ is the law of motion of the aggregate capital stock.

The firm of course, simply maximizes its period profits and hence does not have a multiperiod problem.

The following functions that are a solution to the individual and firm maximization problem above satisfy the definition of Recursive Competitive Equilibrium:

(a) A value function $v\left(k_{0}, \underline{k}_{0}, \lambda_{0}\right)=E\left\{\sum_{t=0}^{\infty} \beta^{t} \ln \left[(1-\alpha \beta) \lambda_{t} \underline{k}_{t}^{\alpha-1}\left\{\alpha\left(k_{t}-\underline{k}_{t}\right)+\underline{k}_{t}\right\}\right]\right\}$. It can be shown that $v\left(\underline{k}_{0}, \underline{k}_{0}, \lambda_{0}\right)=A+B \ln \underline{k}_{0}+C \ln \lambda_{0}$ where A,B and $\mathrm{C}$ are constants which are functions of the preference and technology paramerers.

(b) A continuous pricing function $p\left(\underline{k}_{t}, \lambda_{t}\right)=\left\{p_{c}\left(\underline{k}_{t}, \lambda_{t}\right), p_{i}\left(\underline{k}_{t}, \lambda_{t}\right), p_{k}\left(\underline{k}_{t}, \lambda_{t}\right), p_{l}\left(\underline{k}_{t}, \lambda_{t}\right)\right\}$

that has the same dimensionality as the commodity point, where

$$
\begin{aligned}
& p_{c}\left(\underline{k}_{t}, \lambda_{t}\right)=p_{i}\left(\underline{k}_{t}, \lambda_{t}\right)=1 \text { (We have chosen the consumption good to be the numeraire.) } \\
& p_{k}\left(k_{t}, \lambda_{t}\right)=\alpha \lambda_{t} \underline{k}_{t}^{\alpha-1} \\
& p_{l}\left(k_{t}, \lambda_{t}\right)=(1-\alpha) \lambda_{t} \underline{k}_{t}^{\alpha-1}
\end{aligned}
$$


(c) Consumption and investment functions for the individual that are a function of the current state of the individual $(k, \underline{k}, \lambda)$

$$
\begin{aligned}
& c^{d}\left(k_{t}, \underline{k}_{t}, \lambda_{t}\right)=(1-\alpha \beta) \lambda_{t} \underline{k}_{t}^{\alpha-1}\left\{\alpha\left(k_{t}-\underline{k}_{t}\right)+\underline{k}_{t}\right\} \\
& l^{s}\left(k_{t}, \underline{k}_{t}, \lambda_{t}\right)=1 \\
& i^{d}\left(k_{t}, \underline{k}_{t}, \lambda_{t}\right)=\alpha \beta \lambda_{t} \underline{k}_{t}^{\alpha-1}\left\{\alpha\left(k_{t}-\underline{k}_{t}\right)+\underline{k}_{t}\right\} \\
& k^{s}\left(k_{t+1}, \underline{k}_{t+1}, \lambda_{t+1}\right)=i^{d}\left(k_{t}, \underline{k}_{t}, \lambda_{t}\right)
\end{aligned}
$$

(d) Decision rules for the firm that are contingent on the state of the economy $(\underline{k}, \lambda)$

$$
\begin{aligned}
& c^{s}\left(\underline{k}_{t}, \lambda_{t}\right)=(1-\alpha \beta) \lambda_{t} \underline{k}_{t}^{\alpha}, \\
& l^{d}\left(\underline{k}_{t}, \lambda_{t}\right)=1 \\
& i^{s}\left(\underline{k}_{t}, \lambda_{t}\right)=\alpha \beta \lambda_{t} \underline{k}_{t}^{\alpha}, \\
& k^{d}\left(\underline{k}_{t+1}, \lambda_{t+1}\right)=i^{s}\left(\underline{k}_{t}, \lambda_{t}\right)
\end{aligned}
$$

(e) The law of motion for the capital stock specifying the next period capital stock as a function of the current state of the economy $\left(\underline{k}_{t}, \lambda_{t}\right)$

$$
\underline{k}_{t+1}=\psi\left(\underline{k}_{t}, \lambda_{t}\right)=\alpha \beta \lambda_{t} \underline{k}_{t}^{\alpha}
$$

(f) The consumption and investment decisions of the individual $c^{s}(k, \underline{k}, \lambda), l^{s}(k, \underline{k}, \lambda)$ and $i^{s}(k, \underline{k}, \lambda)$ maximize the expected utility subject to the budget constraint. So that

$$
v\left(k_{t}, \underline{k}_{t}, \lambda_{t}\right)=\ln \left((1-\alpha \beta) \lambda_{t} \underline{k}_{t}^{\alpha-1}\left(\alpha\left(k_{t}-\underline{k}_{t}\right)+\underline{k}_{t}\right)\right)+\beta \int v\left(\alpha \beta \lambda_{t} \underline{k}_{t}^{\alpha-1}\left(\alpha\left(k_{t}-\underline{k}_{t}\right)+\underline{k}_{t}\right), \alpha \beta \lambda_{t} \underline{k}_{t}^{\alpha}\right) d F\left(\lambda_{t+1} \mid \lambda_{t}\right)
$$

(g) The decision rules of the firm $c^{d}\left(\underline{k}_{t}, \lambda_{t}\right), l^{d}\left(\underline{k}_{t}, \lambda_{t}\right), i^{d}\left(\underline{k}_{t}, \lambda_{t}\right)$ maximize firm profit.

Demand equals supply

$c^{d}\left(k_{t+1}, \underline{k}_{t+1}, \lambda_{t+1}\right)=c^{s}\left(\underline{k}_{t}, \lambda_{t}\right), l^{s}\left(k_{t+1}, \underline{k}_{t+1}, \lambda_{t+1}\right)=l^{d}\left(\underline{k}_{t}, \lambda_{t}\right)$ and $i^{s}\left(k_{t+1}, \underline{k}_{t+1}, \lambda_{t+1}\right)=i^{d}\left(\underline{k}_{t}, \lambda_{t}\right)$ 
The law of motion of the representative consumers capital stock is consistent with the maximizing behavior of agents $\psi\left(\underline{k}_{t}, \lambda_{t}\right)=i^{d}\left(\underline{k}_{t}, \underline{k}_{t}, \lambda_{t}\right)$.

It is readily demonstrated that since $v\left(\underline{k}_{0}, \underline{k}_{0}, \lambda_{0}\right)=w\left(\underline{k}_{0}, \lambda_{0}\right)$, the competitive allocation is Pareto optimal ${ }^{6}$.

Having formulated expressions for the prices of the various assets and their laws of motion, it is a relatively simple matter to calculate rates of return (price ratios) and study their dynamics. For an application to risk premia, see Donaldson and Mehra (1984). Some researchers have formulated models that can be cast in this same recursive setting, yet whose equilibria are not Pareto-optimal. As a consequence, the model's equilibrium can no longer be obtained as the solution to a central-planning-optimum formulation. These models incorporate various features of monetary phenomena, distortionary taxes, non-competitive labor market arrangements, externalities, or borrowing-lending constraints. Besides increasing general model realism, such features not only enable the models to better replicate the stylized facts of the business cycle, but also to provide a rationale for interventionist government policies. Monetary models of this class include those of Lucas and Stokey (1987, a monetary exchange model) and Coleman (1996, a monetary production model). Bizer and Judd (1989) and Coleman (1991) present models in which non-optimality is induced by tax distortions while Danthine and Donaldson (1990) present a model in which non-optimality results from efficiency-wage considerations. In these models, equilibrium is characterized as an aggregate-consumption

\footnotetext{
${ }^{6}$ See equations (P1) and (P2).
} 
and an aggregate-investment function which jointly solves a system of first-order optimality equations on which market-clearing conditions have been imposed. Coleman (1991) provides a widely applicable set of conditions under which these suboptimal equilibrium functions exist. As already noted, however, these optimality conditions cannot, in general, characterize the solution to an optimum problem. 


\section{Bibliography}

Bewley, T. 1972. "Existence of Equilibria in Economies with Infinitely Many

Commodities." Journal of Economic Theory 4:514-40.

Bizer, D. and K. Judd. 1989. "Taxation and Uncertainty." American Economic Review Papers and Proceedings 19:331-36.

Brock, W.A. and L.J. Mirman. 1972. "Optimal Economic Growth and Uncertainty: The Discounted Case." Journal of Economic Theory 4:497-513.

Cass, D. 1965. "Optimal Growth in an Aggregative Model of Capital Accumulation." Review of Economic Studies 32:233-40.

Coleman, W.J. 1991. "Equilibrium in a Production Economy with an Income Tax." Econometrica 59:1091-1104.

_-_-_-_.1996. "Money and Output: A Test of Reverse Causation." American Economic Review 86:90-111.

Danthine, J.P. and J.B. Donaldson. 1990. "Efficiency Wages and the Business Cycle Puzzle." European Economic Review 34:1275-1301.

Donaldson, J.B. and R. Mehra. 1983. "Stochastic Growth with Correlated Production Shock." Journal of Economic Theory 29:282-312.

Harris, M. 1987. Dynamic Economic Analysis. New York: Oxford University Press. Kydland, F.E. and E.C. Prescott. 1982. "Time to Build and Aggregate Fluctuations." Econometrica, 50: 1345-1371. 
Ljungquist, L. and T.J. Sargent. 2004. Recursive Macroeconomic Theory. $2^{\text {nd }}$ edition. Cambridge: MIT Press.

Long, J.B. Jr. and C.I. Plosser. 1983. "Real Business Cycles." Journal of Political Economy, 91:39-69.

Lucas, R.E., Jr. and N. Stokey. 1987. "Money and Interest in a Cash Advance Economy." Econometrica 55:491-513.

Mehra, R. 1988. "On the Existence and Representation of Equilibrium in an Economy with Growth and Non-Stationary Consumption." International Economic Review 29:131-35.

Mehra, R. and E.C. Prescott. 1977. "Recursive Competitive Equilibria and Capital Asset Pricing." in Essays in Financial Economics. Doctoral Dissertation, R. Mehra, Carnegie Mellon University. UMI, Ann Arbor, Michigan.

Mehra R. and E.C. Prescott. 1985. "The Equity Premium: A Puzzle." Journal of Monetary Economics, 15: 145-162.

Prescott, E.C. and R.E. Lucas, Jr. 1972. "A Note on Price Systems in Infinite Dimensional Space." International Economic Review 13:416-22.

Prescott, E.C. and R. Mehra. 1980. "Recursive Competitive Equilibria: The Case of Homogeneous Households." Econometrica 48:1365-79.

Stokey, N., R.E. Lucas, and E.C. Prescott. 1989. Recursive Methods in Economic Dynamics. Cambridge: Harvard University Press. 